\title{
Towards Defining a Competence Profile for the Enterprise Modeling Practitioner
}

\author{
Anne Persson ${ }^{1}$ and Janis Stirna ${ }^{2}$ \\ ${ }^{1}$ University of Skövde, Informatics Research Centre, P.O. Box 408, \\ SE-541 28 Skövde, Sweden \\ anne.persson@his.se \\ ${ }^{2}$ Department of Computer and Systems Sciences, Stockholm University, Forum 100, \\ SE-1644 0, Kista, Sweden \\ js@dsv.su.se
}

\begin{abstract}
Enterprise Modeling (EM) has established itself as a valuable instrument for various purposes related to organizational development, such as designing or redesigning the business, eliciting requirements for information systems, capturing and reasoning about organizational knowledge. A notable characteristic of EM is its collaborative way of stakeholder involvement in modeling. Much of the success of projects using EM depends on how the EM process is organized and on the competence level of the expert responsible for the EM approach. This paper analyses what are the competence needs for the method expert and what competences are needed in the different steps in the EM process. The EM process described consists of activities for project inception and planning, conducting modeling sessions, and delivering a result that can be taken up by a subsequent implementation project. Two main competence areas are discussed in relation to the EM process - competences related to modeling and competences related to managing EM projects.
\end{abstract}

Keywords: Enterprise modeling, modeling practitioner, competence profile.

\section{Introduction}

Enterprise Modeling (EM) is a process where an integrated and negotiated model describing different aspects of an enterprise is created. An Enterprise Model consists of a number of related "sub-models", each describing the enterprise from a particular perspective, e.g. processes, business rules, goals, actors and concepts. EM has for some years been a central theme in information systems (IS) engineering research. There are two main reasons for using EM [1]:

Developing the business - this entails developing business vision, strategies, redesigning the way the business operates, developing the supporting information systems, capturing IS requirements, etc.

Ensuring the quality of the business - here the focus is on two issues: 1) sharing the knowledge about the business, its vision, the way it operates, and 2) ensuring the acceptance of business decisions through committing the stakeholders to the decisions made. 
Examples of EM methods can be found in [2, 3, 4, 5, 6, 7, 8, 9, 10, 11, and 12]. Examples of application domains for EM can be found in $[13,14,15,16,17,18,19$ and 20].

Some method developers have advocated a participatory way of working (see e.g. [7, 8, and 21]). In facilitated group modeling, participation is consensus-driven in the sense that it is the domain stakeholders who "own" the model and govern its contents. In contrast, consultative participation means that analysts create models and domain stakeholders are then consulted in order to validate the models.

In the participatory approach to EM, stakeholders meet in modeling sessions, led by a facilitator, to create models collaboratively. In the modeling sessions, models are often documented on large plastic sheets using paper cards. The "plastic wall" is viewed as the official "minutes" of the session, for which every participant is responsible. Establishing effective and consensus-driven participation requires:

- $\quad$ achieving active communication and lively discussion between individuals and between groups of individuals. This increases the chances of identifying different views on the problem to be discussed.

- $\quad$ creating a group, i.e. to make people feel that they work towards the same goal which increases the chances of achieving a good modelling result.

More on the participative approach to EM can be found e.g. in [8 and 21]. The EM process described in this paper is based on the view that a participatory way of working is the main approach to EM.

A large amount of research has been dedicated to the development of new modeling languages and to the refinement of existing EM languages, while their use in practice has attracted much less attention. EM practice can be discussed from a number of alternative perspectives, such as e.g.:

- the ability of modeling languages to express aspects of the domain being modeled,

- the usability of modeling languages,

- the role of enterprise models in information systems engineering,

- the effect on the systems development process of using enterprise models, and

- the applicability of modeling languages in different contexts.

This paper addresses a perspective on EM that has been more or less neglected in the scientific literature: the competency of the modeling practitioner. Some references exist (see e.g. [7, 8 and 21]), which mainly focus on the modeling expert in her/his capacity as facilitator. We have not found any previous research that takes a broader view on the competency required throughout a whole EM project.

Therefore, the goal of the paper is to define a set of core competencies for the modeling practitioner and to relate these core competencies to a detailed stereotype EM project process. A modeling practitioner is defined as someone who is responsible for running part of or the whole EM project process towards effectively achieving its goals.

The remainder of the paper is organized as follows. Section 2 discusses the concept of EM competence. In Section 3 the research approach is presented. The process of a stereotypical EM project is defined in Section 4, while the core competences related to the defined EM process are included in Section 5. The paper ends with some concluding remarks in Section 6. 


\section{EM Competence - A Critical Resource to Achieve the Goals of EM}

Human knowledge and competence is a critical resource for achieving the goals of EM. There are two reasons for this:

- Models contain human knowledge about an organization in its current or perceived future state. We need domain experts who contribute this knowledge.

- The knowledge that domain experts have needs to be captured and structured in enterprise models that contribute to the EM goals. We need modeling practitioners who are able to do this.

The concept of competency is complex and can be defined in a number of ways. For the purposes of this paper we state that competency has four main aspects:

1) Knowledge - a person's factual knowledge about a specific subject matter, as a result of e.g. education.

2) Skills- a person's ability to actually use the knowledge to achieve goals.

3) Individual properties- a wide range of personal characteristics e.g. social skills, intelligence, flexibility, integrity, ability to co-operate, courage etc.

4) Willingness to contribute competency - a person's attitude towards actually contributing her/his knowledge and skills to the achievement of goals other than her/his own.

In this paper we concentrate on skills and individual properties, and we particularly target the competence of the modeling practitioner. In the following we give an overview of the roles in EM.

An Enterprise Model comprises knowledge about different aspects of some organization in its current or perceived future state. Domain experts provide this knowledge and are responsible for the correctness and relevance of that knowledge in the context of the EM project.

To create the Enterprise Models, using a participative approach, a modeling practitioner is needed. This is the role that the professional EM practitioner plays in an EM project. They can take on a number of sub-roles, e.g. EM project leader, facilitator of a modeling session, and tool expert. As project leader, the modeling practitioner negotiates and plans the modeling project together with the project or problem owner. A facilitator moderates each modeling session. In a session there can be more than one facilitator and also a tool expert. A larger modeling project will typically have several facilitators and tool experts forming a modeling practitioner team, which is headed by project leader. The team leader should be an experienced facilitator.

Figure 1 shows the main difference in responsibilities of domain experts and modeling practitioners. Arguments for this separation of responsibilities are given in [22].

The main responsibility of the modeling practitioner is that the models produced have good enough quality to accomplish the project goals. It is also to ensure that the chosen EM method is suitable for modeling the problem at hand and that the method is effectively used to accomplish the project goals. This means not only to use the 


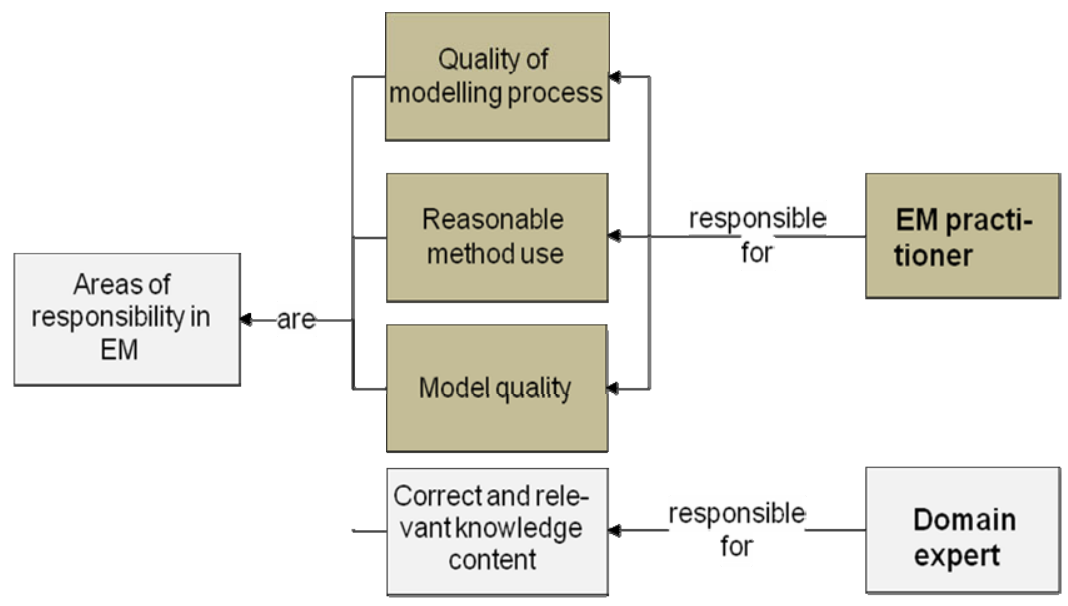

Fig. 1. Actors in EM and their responsibilities

method's notation in a reasonable way but to also construct and to run a modeling process that makes the best of available resources, e.g. the knowledge and abilities of domain experts. The modeling practitioner is also responsible for making sure that the project resources are used in a way that enables the modeling project to be completed on time and in such a way that the goals are achieved.

The main challenge of the EM process is to ensure that the quality of its outcome is fit for the intended use. Potential outcomes of EM are, e.g., models, decisions and enhanced knowledge among those involved in the EM process. Since the EM process is highly intellectual, it is dependent on the competence of its participants. If the proper EM competence is not available in the EM process, the effects of EM will not appear. In the following we will focus on the competence of the EM practitioner.

\section{Research Approach}

The research approach taken in this paper follows the principles of design science [23]. This section discusses how the seven guidelines [ibid] of design science have been addressed in this research.

Guidelines 1: Design as an Artifact. We consider the competence profile for EM practitioners and its alignment to the EM process a design artifact. It contributes to making EM approaches more operational, i.e. easy to use in practice.

Guideline 2: Problem Relevance. Many organizations struggle to adopt EM and to carry out EM projects. Currently the knowledge of what competences and skills are needed in a successful project is to a large extent tacit possessed by only a few experienced EM practitioners. Hence, this knowledge should be captured and presented in such a way it can be applied by a broad range of practitioners. The need for addressing the competence issue in EM is supported by interview studies on the practice of EM reported in [22] and on the EM tool usage in [24]. 
Guideline 3: Design Evaluation. The proposed design artifact has been validated by informed arguments and its internal consistency has been ensured by linking the proposed competence profile to the EM process. In addition the proposed competence profile has been applied in field studies of staffing and carrying out real life EM projects. More about some of these projects is available [25].

Guideline 4: Research Contribution. To the best of our knowledge the competence needs for EM is relatively unexplored and similar competence profile linked to the steps of the EM process does not currently exist.

Guideline 5: Research Rigor. The initial theoretical constructs of how EM application projects should be organized and carried out emerged from grounded theory studies reported in [22 and 24], projects such as F3 [8], ELEKTRA [26] and HyperKnowledge [27 and 28]. The findings were further extended by participating in and analysis experiences from EM activities in projects such as Mapper [29, 30] and InfoFlow [31]. All together the findings are based on more than 100 modeling sessions during the years from 1993 to present.

Guideline 6: Design as a Search Process. We have developed the proposed artifact iteratively and incrementally over numerous cycles going from generating alternatives to then validating them against real life requirements for EM projects and back.

Guideline 7: Communication of Research. [23] suggest that "design science research should be presented to technology-oriented as well as management audiences". The interpretation of this in our case is that the proposed competence profile for EM experts should be presented both to researchers developing new EM approaches and tools as well as to practitioners using these EM technologies. Hence, we choose PoEM as the most suitable forum to present our research.

\section{Enterprise Modeling Projects - A Process View}

This section presents the EM process, shown in figure 2. We consider this a stereotyped process, because in real life projects the actual steps and information sets might differ slightly. It is also possible that additional steps are needed, e.g. to ensure integration with another development project or to involve a broad group of stakeholders.

The EM process follows generic principles of carrying out projects for various purposes. This is because we strongly believe that aligning EM activities with the general project activities improves stakeholder acceptance of the modeling way of working.

Table 1 shows how different actors are involved in the steps of the EM process.

Process 1: Define scope and objectives of the EM project. We assume that the EM project is commissioned either as a result of selling consulting services or another inhouse development project has decided to address a specific problem area by a modeling approach. In either case there usually exists an initial problem statement (inf. set 1) and an organizational actor that will benefit from solving the problemproblem owner. At this stage the problem owner and the EM project leader should discuss the problem to find its boundaries, what the likely ways of solving it might be, and what the expected outcomes are. This would form a project definition (inf. set 3 ). In this process model we assume that the organization has already assessed its suitability for using the participative approach to EM, but if has not been done, or 


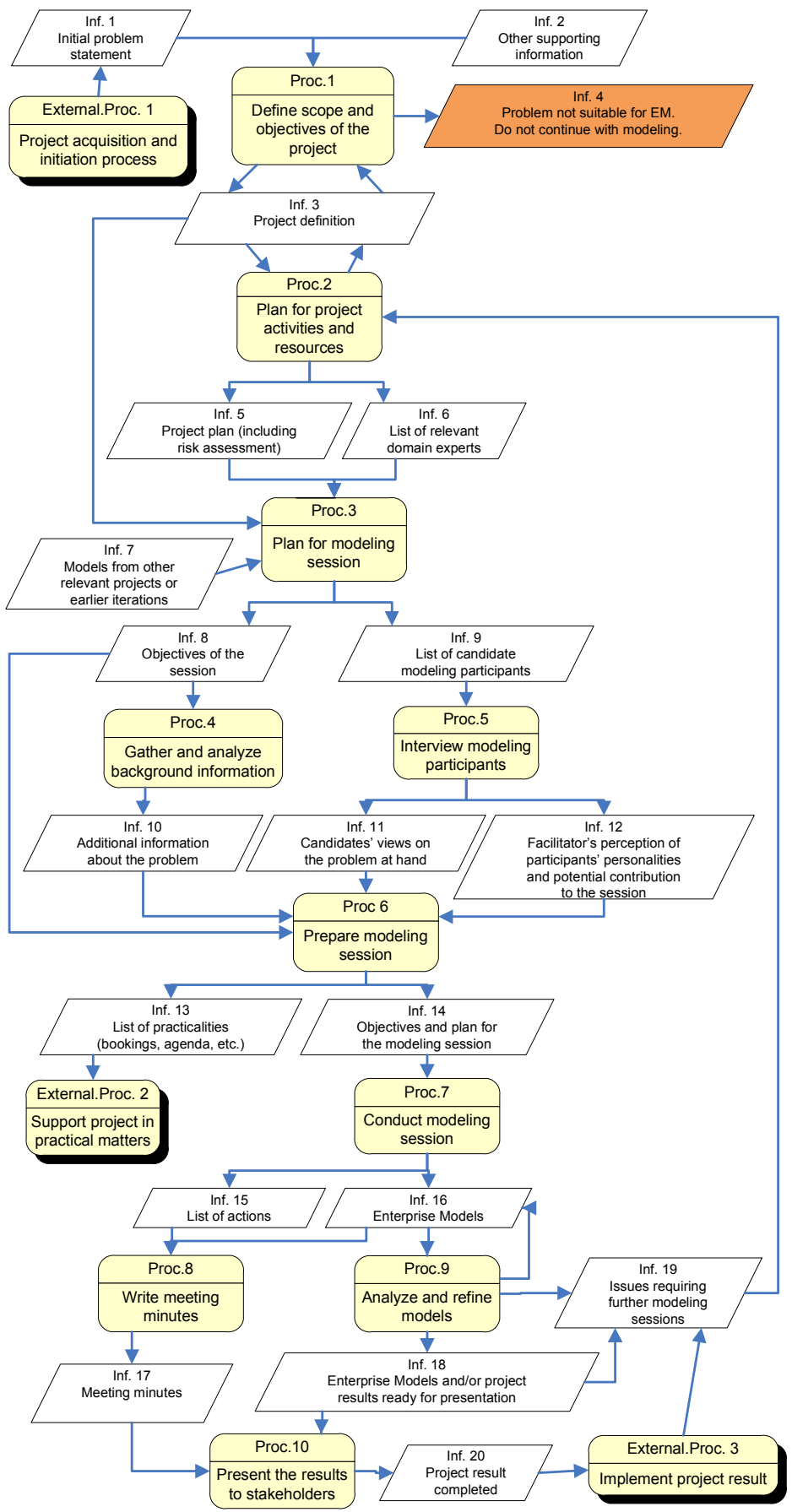

Fig. 2. The EM process model showing processes and information sets 
Table 1. Actor involvement in the EM process steps (R- responsible, P-participates)

\begin{tabular}{|l|l|l|l|l|l|}
\hline EM Process Step & $\begin{array}{l}\text { Problem } \\
\text { owner }\end{array}$ & $\begin{array}{l}\text { Domain } \\
\text { expert }\end{array}$ & $\begin{array}{l}\text { EM project } \\
\text { leader }\end{array}$ & $\begin{array}{l}\text { EM } \\
\text { facilitator }\end{array}$ & $\begin{array}{l}\text { Tool } \\
\text { expert }\end{array}$ \\
\hline P1 Define scope and objectives of the project & $\mathrm{R}$ & & $\mathrm{P}$ & & \\
\hline P2 Plan for project activities and resources & $\mathrm{R}$ & & $\mathrm{P}$ & $\mathrm{P}$ & \\
\hline P3 Plan for modeling session & $\mathrm{P}$ & & $\mathrm{R}$ & $\mathrm{P}$ & \\
\hline P4 Gather and analyze background information & & & $\mathrm{P}$ & $\mathrm{R}$ & \\
\hline P5 Interview modeling participants & & $\mathrm{P}$ & & $\mathrm{R}$ & \\
\hline P6 Prepare modeling session & $\mathrm{P}$ & & $\mathrm{P}$ & $\mathrm{R}$ & \\
\hline P7 Conduct modeling session & & $\mathrm{P}$ & & $\mathrm{R}$ & $\mathrm{P}$ \\
\hline P8 Write meeting minutes & & & $\mathrm{P}$ & $\mathrm{R}$ & $\mathrm{P}$ \\
\hline P9 Analyze and refine models & $\mathrm{P}$ & & $\mathrm{P}$ & $\mathrm{R}$ & $\mathrm{P}$ \\
\hline P10 Present the results to stakeholders & $\mathrm{R}$ & $\mathrm{P}$ & $\mathrm{P}$ & $\mathrm{P}$ & \\
\hline
\end{tabular}

some doubts arise (e.g. a strong sense of hidden agendas) then the EM project leader should assess the situation in the organization. The problem should also be assessed for being suitable for EM. More about assessing the organization and the problem at hand is available in, e.g. [21, 22, and 29]. If the organization or the problem is found to be unsuited for EM, then the problem owner and the project leader should choose other ways of solving the problem, e.g. by the consultative approach or by brainstorming. When dealing with complex and/or wicked problems [32] it might be difficult to formulate a clear problem definition. In such cases the project might organize a modeling session with an objective to find out what the real problem is and how to tackle it.

Process 2. Plan for project activities and resources. At this stage the EM project leader, problem owner and facilitator plan specific activities to be carried out. This includes the overall number and schedule of modeling sessions, the issues addressed in them (inf. set 5), as well as indicating relevant domain experts to be involved in the modeling sessions later (inf. set 6). Additional issues to pay attention at this stage are risk assessment, resource allocation, both for the method provider team and for the domain experts, and establishing project groups' overall authority, i.e. mandate to solve the problem.

Process 3. Plan for modeling session. The objective is to plan a specific modeling session, i.e. to set its overall objective and questions to be addressed (inf. set 8). Existing models produced in previous modeling session of the project or earlier projects in the organization and/or other supporting information might also be analyzed. The initial list of relevant domain experts (inf. set 6) should be analyzed and candidates for involving in the modeling session should be selected (inf. set 9).

Process 4 Gather and analyze background information. The modeling facilitator usually needs to obtain additional information to learn more about the organization and the background of the problem at hand.

Process 5. Interview modeling participants. The candidates for involving in the modeling session (inf. set 9) are interviewed individually in order to learn more about their views on the problem at hand (inf. set 11) and to assess the participant's potential contribution at the modeling session (inf. set 12). A benefit for the candidate is that he/she is able to learn about the project and the upcoming modeling session in advance. In some projects it is beneficial to interview more participants that are going 
to be used in the modeling sessions, because this allows the project team to learn more about the organization and, indirectly, to spread the word about the project and the coming change in the organization.

Process 6. Prepare modeling session. At this stage a detailed plan for the modeling session (inf. set 14) is elaborated by analyzing the background material and findings from the interviews. This plan should include specific objectives the modeling session, specific questions to be addressed, preliminary set of enterprise models to be developed (e.g. goal models, concepts models, actor models), a set of driving questions for starting the discussion, the expected level of model quality. The modeling facilitator should also assess various risks and scenarios of how the modeling session might develop. E.g. what are the topics that the participants will not talk willingly, what are the topics that might lead the discussion astray, what can cause conflicts, how to act in case of a conflict. This should be done in collaboration with the problem owner and project leader. The practicalities of the meeting (inf. set 13) should also be organized, which includes location, agenda, travel plans, etc.

Process 7. Conduct modeling session. The objective of this paper is not to describe details of how a modeling session is conducted. Recommendations of what to do and what not to are available, for example, in [29, 30, 33, 34, and 35]. The tangible outcome of the modeling session is the models produced (inf. set 16) and an additional list of actions for implementing the decisions made during the modeling session (inf. set 15). Additional intangible outcomes of modeling are participants' improved understanding of the problem area and a firmer commitment to the decisions made [22 and 36].

Process 8. Write meeting minutes. After the modeling session it is recommended to write minutes of the meeting (inf. set 17) which includes the models as in the state were produced at the modeling seminar and action list. At this stage the models should not be more refined because the main purpose of this activity is to send notes to the participants which might also serve as a reminder of the actions that they have agreed to be responsible for.

Process 9. Analyze and refine models. Enterprise Models created at a modeling session usually need further refinement in terms of presentation and layout, as well as content. The result of the modeling session should also be analyzed with respect to the objectives of the session and the project. This either leads the project team to a conclusion that the expected result is achieved and can be presented to the organization (inf. set 18). Otherwise the team indentifies a set of issues for further development and modeling (inf. set 19) and proceeds with planning subsequent project activities (process 2). In many cases information sets 18 and 19 are reports of the project activities.

Process 10. Present the results to stakeholders. The modeling project ends with presenting the results to the problem owner and relevant stakeholders. A part of this presentation is decision making on how the results should be implemented or takenup by the organization. It might also be that the stakeholders indentify issues that are not resolved and require further development (inf. set 19).

The EM process we have outlined ends when the problem owner and the involved stakeholders feel that they have a result that can be implemented. In practice the EM project results will most likely serve as input for another development project, including an IT or IS development project. 
The EM process described in this section may appear easy to conduct on the outset. In reality however there are many challenges to succeed and pitfalls to avoid, particularly in the project preparation phase (processes 1 to 6). Much of this knowledge is related to organizational and social issues and hence is not easily formalizable. For example, in [34] we have proposed to capture some of this knowledge in the form or anti-patterns. But in addition to capturing and sharing knowledge about best and worst practices, much of the success depends also on the competence of the modeling facilitator, which we will discuss in the next section.

\section{Core Competences in Enterprise Modeling Projects}

Previous research [22] has identified three levels of EM practitioner competence:

- Ability to model, which means that a person is able to construct an Enterprise Model which is syntactically correct according to the used EM language and that the model in a reasonable way reflects the domain and problem in question.

- Ability to facilitate modeling sessions, which means that a person is able to lead a group of domain experts in creating/refining an Enterprise Model and doing it in such a way that the group's knowledge and abilities work together to create a high quality model.

- Ability to lead EM projects towards fulfilling their goals and making the best of the project resources.

The list of relevant competences that are useful for acting at each level can potentially be very long. We claim that in order to target the main challenge of the EM process, which is to produce an EM outcome that is fit for its intended use, we need to define a set of essential core competences that target the quality of the outcome of EM. In the following we describe the core competences that our research has yielded so far. They fall into two distinct categories: 1) those related to modeling itself, i.e. the ability to model and the ability to facilitate participatory modeling session. These competences are at the heart of modeling and 2) those related to setting up and managing EM projects.

\subsection{Competences Related to Modeling}

The ability to model involves making use of the chosen EM language to create and refine enterprise models. The resulting models should reflect the discussion in the modeling session and focus on the problem at hand. Knowing how to use modeling tools for documenting and analyzing the modeling result is also included in this ability. One important, and sometimes neglected, aspect is the ability to create a readable model, because they tend to become large and graphically complex.

Since we advocate a participatory approach to EM, the ability to facilitate a modeling session is essential. Facilitation is a general technique used in group processes for a wide variety of purposes, also within EM (see further e.g. [37] and International Association for Facilitators (IAF) http://www.iaf-world.org). This ability is very much based on knowledge about the effects of modeling, the principles of human communication and socialization (especially in groups), as well as the conditions of human learning and problem solving (cognition). For EM, some of the 
more important aspects of this competence are to condense and capture important ideas, to pose questions that trigger discussion, to listen, to summarize and generalize, as well as to drive the discussion towards fulfilling the goals of the EM session.

For both of these abilities we want to highlight the fact that the competence requirements are quite different if $\mathrm{EM}$ is used to capture the current situation compared to designing a future situation. In the latter case the ability of the EM practitioner will be geared towards drawing out the creativity of the domain experts and to guide that creativity towards the goals of the session.

\subsection{Competences Related to Managing EM Projects}

In order for the models to be fit for their intended use, the EM practitioner needs the ability to select an appropriate EM approach and tailor it in order to fit the situation at hand. Sometimes that choice is restricted by the requirements of the context of use, as e.g. is the case when EM is used in an IS development project that uses a particular method and tool-set. In other cases the choice of EM approach is up to the EM practitioner. Based on her/his knowledge about the problem at hand, the requirements on the EM result, the preferences and modeling skill level of the modeling group, and the context in which EM will be used the EM practitioner will choose an appropriate approach. The professional EM practitioner will have a "tool-box" of potential methods for different purposes that she/he is able to use. Independently of whether the EM practitioner has the choice of approach, the approach often needs to be tailored to fit the situation at hand and she/he will then need to be able to assess the consequences of any changes made to the approach.

In participatory EM the ability to interview involved domain experts before the EM session is critical. In this situation the social skills of the EM practitioner are essential, such as e.g. ability to listen, ability to read body language. In a discrete way the EM practitioner needs to ask the domain expert what should be talked about in the modeling session and also try to find out what topics should be avoided and why.

For EM to have effect in its context of use, it needs to be focused towards a particular goal or problem. This pertains both to the overall EM project level and to each EM session. The ability to define a relevant problem that is feasible to model based on the information that the EM practitioner can obtain is, therefore, important. This ability is very much related to the ability to interview domain experts. In this ability the capacities to conceptualize, generalize and to assess the relationships between different problems are included. An essential aspect of defining the relevant problems is the ability to spot hidden agendas, which builds both on the practitioner's previous experience but also on her/his social skills and ability to "read between the lines" in a conversation. Unidentified hidden agendas can potentially cause problems later on in the EM project. Assessing the complexity of a problem is also part of defining a problem. Problem complexity is a heavy influence on the planning of the project both in terms of activities and resources. It can be argued that it is impossible to define a clear problem on the outset and that it will change as the project proceeds. This is true, but in order for the project to become operative at least a "working problem" is needed.

In planning an EM project and an EM session the ability to define requirements on the results are essential in order for project/session goals to be achieved. These requirements relate to the models that are to be produced as well as what is to be 
achieved by these models. Sometimes the requirements have to do with the process itself. E.g. by involving certain stakeholders and having them listen to what other stakeholders have to say in a participatory EM session, certain change decisions can be made less dramatic for the organization. The EM practitioner should also keep in mind that the models produced is the tangible result of modeling, but equally important is the intangible result - participants' changed thinking and understanding of the problem.

The ability to establish a modeling project is critical in order to create the most beneficial conditions for the EM project. Favorable conditions will increase the chances of obtaining the desirable effects of EM. Conditions involve resources in terms of time and competence (domain as well as EM practitioner competence) as well as authority for EM project participants to act freely and make decisions within the project definition. This ability is essential in any project.

The result of modeling will be used for a specified purpose. In order for that purpose to be fulfilled the users of the result need to understand it and its implications. This means that the modeling practitioner will have to present it in oral and/or written form to them. Depending on the target audience, certain aspects of the result will need to be emphasized or toned down. E.g. presenting project results to a group of managers the detailed data structure of the supporting IS can be omitted. This requires an ability to adjust a presentation of project results and issues related to them to various stakeholders.

An EM project is a signal to the organization that change of some kind is imminent. This means that various stakeholders will try to influence the EM practitioner so that their own goals will be those of the EM project. To navigate between the wishes of various stakeholders while upholding the EM project goal is, therefore, a critical competence. More about the challenges involved in tackling this problem can be found in [38].

EM projects typically deliver a solution to a business problem. The solution usually consists of an organizational design proposal (which might include an IT solution) reflected in Enterprise Models. A partially intangible outcome of the EM project is the supporting set of decisions and commitment to implement the solution.

Table 2. Matching of EM process steps to core competences

\begin{tabular}{|c|c|c|c|c|c|c|c|c|c|c|}
\hline Process & P1 & $\mathrm{P} 2$ & P3 & P4 & P5 & P6 & P7 & P8 & P9 & P10 \\
\hline to model & & & & & & & $\mathrm{X}$ & & $\mathrm{X}$ & \\
\hline to facilitate modeling sessions & & & & & & & $\mathrm{X}$ & & & \\
\hline to interview involved domain experts & & & & & $\mathrm{X}$ & & & & & \\
\hline to define a problem & $X$ & & $X$ & & & $X$ & & & $X$ & \\
\hline to define requirements on the results & $\mathrm{X}$ & $\mathrm{X}$ & $\mathrm{X}$ & & & & & & & \\
\hline to establish a modeling project & $\mathrm{X}$ & & & & & & & & & \\
\hline to adjust presentation of project results & & & & & & $X$ & & & & $\mathrm{X}$ \\
\hline $\begin{array}{l}\text { to navigate between the wishes of } \\
\text { stakeholders while upholding a defined } \\
\text { project strategy }\end{array}$ & $\mathrm{X}$ & $\mathrm{X}$ & & & $\mathrm{X}$ & & $\mathrm{X}$ & & & $\mathrm{X}$ \\
\hline $\begin{array}{l}\text { to assess the impact of the modeling result and } \\
\text { the modeling process in the organization }\end{array}$ & $\mathrm{X}$ & $\mathrm{X}$ & & & & $\mathrm{X}$ & & & $\mathrm{X}$ & $\mathrm{X}$ \\
\hline
\end{tabular}


An example issues to consider are: would the solution appear to be inappropriately bureaucratic, democratic, authoritative; what kind of implementation activities are needed, etc. An ability to assess the impact of the modeling result and the modeling process in the organization is therefore needed to drive the modeling effort towards a solution that has a high probability of being implemented within the organization.

In Table 2 the core competences are summarized and mapped to the process steps defined in Figure 1.

\section{Concluding Remarks}

In this paper we have identified a set of core competencies based on a large number of EM projects and EM sessions conducted during more than 10 years. One important message in our findings is that the quality of the outcome of EM does not only depend on the practitioner's ability to model and to lead modeling sessions. At least as important is the EM practitioner's ability to manage an EM project. This means that being a professional EM practitioner involves integrating core modeling activities into an overall EM project management process that is geared towards effectively fulfilling the goals of the EM project. As a consequence, the role of managing EM projects is not something for the inexperienced EM practitioner.

Looking at EM education and training, particularly in the university context, it is mostly focused on the ability to model. Often it is assumed that with that ability comes, automatically, the ability to facilitate modeling sessions and particularly to manage EM projects. Based on our research we find that this is clearly not the case. In consequence, the education and training of EM practitioners should focus more on aspects related to effectively managing EM in its context of use.

\section{References}

1. Persson, A., Stirna, J.: An explorative study into the influence of business goals on the practical use of Enterprise Modelling methods and tools. In: Tenth International Conference on Information Systems Development (ISD 2001), September 5-7, University of London Royal Holloway (2001)

2. Bajec, M., Krisper, M.: A methodology and tool support for managing business rules in organizations. Information Systems 30(6), 423-443 (2005)

3. Castro, J., Kolp, M., Mylopoulos, J.: A Requirements-Driven Software Development Methodology. In: Dittrich, K.R., Geppert, A., Norrie, M.C. (eds.) CAiSE 2001. LNCS, vol. 2068, pp. 108-123. Springer, Heidelberg (2001)

4. Dobson, J., Blyth, J., Strens, R.: Organisational Requirements Definition for Information Technology. In: Proceedings of the International Conference on Requirements Engineering 1994, Denver/CO (1994)

5. Johannesson, P., Boman, M., Bubenko, J., Wangler, B.: Conceptual Modelling. Prentice Hall International Series in Computer Science. Prentice Hall, Englewood Cliffs (1997)

6. Bubenko Jr., J.A.: Extending the Scope of Information Modelling. In: Fourth International Workshop on the Deductive Approach to Information Systems and Databases, Lloret, Costa Brava Catalonia, September 20-22 Department de Llenguatges i Sistemes Informatics, Universitat Politecnica de Catalunya, Report de Recerca LSI/93-25, Barcelona (1993) 
7. Bubenko Jr., J.A., Persson, A., Stirna, J.: User Guide of the Knowledge Management Approach Using Enterprise Knowledge Patterns. In: Deliverable D3, IST Programme project Hypermedia and Pattern Based Knowledge Management for Smart Organisations, project no. IST-2000-28401, Royal Institute of Technology, Sweden (2001)

8. F3 Consortium, F3 Reference Manual. ESPRIT III Project 6612, SISU, Stockholm (1994)

9. Fox, M.S., Chionglo, J.F., Fadel, F.G.: A common-sense model of the enterprise. In: Proceedings of the 2nd Industrial Engineering Research Conference, Institute for Industrial Engineers, Norcross, GA (1993)

10. Lillehagen, F., Krogstie, J.: Active Knowledge Modeling of Enterprises. Springer, Heidelberg (2008) ISBN: 978-3-540-79415-8

11. Loucopoulos, P., Kavakli, V., Prekas, N., Rolland, C., Grosz, G., Nurcan, S.: Using the EKD Approach: The Modelling Component, UMIST, Manchester, UK (1997)

12. Yu, E.S.K., Mylopoulos, J.: From E-R to "A-R-" Modelling Strategic Actor Relationships for Business Process Reengineering. In: Proceedings of the 13th International Conference on the Entity-Relationship Approach, Manchester, England (1994)

13. Wangler, B., Persson, A., Johannesson, P., Ekenberg, L.: Bridging High-level Enterprise Models to Implemenation-Oriented Models. In: Fujita, H., Johannesson, P. (eds.) New Trends in Software Methodologies, Tools and Techniques. IOS Press, Amsterdam (2003)

14. Niehaves, B., Stirna, J.: Participative Enterprise Modelling for Balanced Scorecard Implementation. In: 14th European Conference on Information Systems (ECIS 2006), Gothberg, Sweden (2006)

15. Stirna, J., Persson, A., Aggestam, L.: Building Knowledge Repositories with Enterprise Modelling and Patterns - from Theory to Practice. In: Proceedings of the 14th European Conference on Information Systems (ECIS 2006), Gothenburg, Sweden (June 2006)

16. Wangler, B., Persson, A.: Capturing Collective Intentionality in Software Development. In: Fujita, H., Johannesson, P. (eds.) New Trends in Software Methodologies, Tools and Techniques, pp. 262-270. IOS Press, Amsterdam (2002)

17. Wangler, B., Persson, A., Söderström, E.: Enterprise Modeling for B2B integration. In: $\mathrm{CD}-\mathrm{ROM}$ proceedings International Conference on Advances in Infrastructure for Electronic Business, Science, and Education on the Internet, , L'Aquila, Italy, August 6-12 (2001)

18. Gustas, R., Bubenko Jr., J.A., Wangler, B.: Goal Driven Enterprise Modelling: Bridging Pragmatic and Semantic Descriptions of Information Systems. In: 5th European - Japanese Seminar on Information Modelling and Knowledge Bases, Sapphoro, May 30-June 3 (1995)

19. Kardasis, P., Loucopoulos, P., Scott, B., Filippidou, D., Clarke, R., Wangler, B., Xini, G.: The use of Business Knowledge Modelling for Knowledge Discovery in the Banking Sector. In: IMACS-CSC 1998, Athens, Greece (October 1998)

20. Carstensen, A., Holmberg, L., Sandkuhl, K.: Supporting Collaboration in an Extended Enterprise with the Connector View on Enterprise Models. In: Proc. of PoEM 2008. LNBIP, vol. 15, pp. 111-126. Springer, Heidelberg (2008)

21. Nilsson, A.G., Tolis, C., Nellborn, C. (eds.): Perspectives on Business Modelling: Understanding and Changing Organisations. Springer, Heidelberg (1999) ISBN 9783540652496

22. Persson, A.: Enterprise Modelling in Practice: Situational Factors and their Influence on Adopting a Participative Approach. Ph.D. thesis, Department of Computer and Systems Sciences, Stockholm University, ISSN 1101-8526 (2001)

23. Hevner, A.R., March, S.T., Park, J., Ram, S.: Design Science in Information Systems Research. MIS Quarterly 28(1), 75-105 (2004) 
24. Stirna, J.: The Influence of Intentional and Situational Factors on EM Tool Acquisition in Organisations. Ph.D. Thesis, Department of Computer and Systems Sciences, Royal Institute of Technology and Stockholm University, Stockholm, Sweden (2001)

25. Stirna, J., Persson, A.: An Enterprise Modeling Approach to Support Creativity and Quality in Information Systems and Business Development. In: Halpin, T., Krogstie, J., Proper, E. (eds.) Innovations in Information Systems Modeling: Methods and Best Practices, IGI Global (December 2008),ISBN 978-1-60566-278-7

http: / / www.igi-global.com/reference/details.asp?ID=33232

26. Bergenheim, A., Persson, A., Brash, D., Bubenko, J.A.J., Burman, P., Nellborn, C., Stirna, J.: CAROLUS-System Design Specification for Vattenfall, Vattenfall AB, Stockholm, Sweden (1998)

27. Mikelsons, J., Stirna, J., Kalnins, J.R., Kapenieks, A., Kazakovs, M., Vanaga, I., Sinka, A., Persson, A., Kaindl, H.: Trial Application in the Riga City Council, deliverable D6, project no. IST-2000-28401 Hypermedia and Pattern Based Knowledge Management for Smart Organizations, Riga, Latvia (2002)

28. Dulle, H.: Trial Application in Verbundplan, deliverable D5, IST Programme project IST2000-28401 Hypermedia and Pattern Based Knowledge Management for Smart Organizations, Verbundplan, Austria (2002)

29. Stirna, J., Persson, A., Sandkuhl, K.: Participative Enterprise Modelling: Experiences and Recommendations. In: Krogstie, J., Opdahl, A.L., Sindre, G. (eds.) CAiSE 2007 and WES 2007. LNCS, vol. 4495, pp. 546-560. Springer, Heidelberg (2007) ISBN 978 -3-540-72987-7

30. Sandkuhl, K., Lillehagen, F.M.: The Early Phases of Enterprise Knowledge Modelling: Practices and Experiences from Scaffolding and Scoping. In: Proc. of PoEM 2008. LNBIP, vol. 15, pp. 1-14. Springer, Heidelberg (2008)

31. Lundqvist, M., Holmquist, E., Sandkuhl, K., Seigerroth, U., Strandesjö, J.: Information Demand Context Modelling for Improved Information Flow: Experiences and Practices. In: Poc. of PoEM 2009. LNBIP, vol. 39, Springer, Heidelberg (2009) ISBN 978-3-64205351-1

32. Rittel, H.W.J., Webber, M.M. (eds.): Planning Problems are Wicked Problems, Developments in Design Methodology, Cross. John Wiley \& Sons, Chichester (1984)

33. Jørgensen, H.D.: Enterprise Modeling - What We Have Learned, and What We Have Not. In: Proc. of PoEM 2009. LNBIP, vol. 39, pp. 3-7. Springer, Heidelberg (2009)

34. Stirna, J., Persson, A.: Anti-patterns as a Means of Focusing on Critical Quality Aspects in Enterprise Modeling. In: Proc. of BMMDS/EMMSAD 2009. LNBIP, vol. 29, pp. 407418. Springer, Heidelberg (2009) ISBN 978-3-642-01861-9

35. Willars, H.: Business Modeller's Checklist: "Dos" and "Don'ts" in Hands-on Practice. In: Nilsson, A.G., Tolis, C., Nellborn, C. (eds.) Perspectives on Business Modelling: Understanding and Changing Organisations, Springer, Heidelberg (1999)

36. Lindström, C.-G.: Lesson Learned from Applying Business Modelling: Exploring Opportunities and Avoiding Pitfalls. In: Nilsson, A.G., Tolis, C., Nellborn, C. (eds.) Perspectives on Business Modelling: Understanding and Changing Organisations, Springer, Heidelberg (1999)

37. Zavala, A., Hass, B.H.: The Art and Power of Facilitation: Running Powerful Meetings, Management Concepts. Inc., Vienna (2008) ISBN 9781567262124

38. Kaarst-Brown, M.L.: Five symbolic roles of the external consultant - Integrating change, power and symbolism. Journal of Organizational Change Management 12(6), 540-561 (1999) 